\title{
Ménétrier's Disease as a Gastrointestinal Manifestation of Active Cytomegalovirus Infection in a 22-Month-Old Boy: A Case Report with a Review of the Literature of Korean Pediatric Cases
}

\author{
Jeana Hong', Seungkoo Lee ${ }^{2}$ and Yoonjung Shon ${ }^{3}$ \\ Department of ${ }^{1}$ Pediatrics, ${ }^{2}$ Anatomic pathology, and ${ }^{3}$ Anesthesiology, Kangwon National University Hospital, Kangwon National University \\ School of Medicine, Chuncheon, Korea
}

\begin{abstract}
Ménétrier's disease (MD), which is characterized by hypertrophic gastric folds and foveolar cell hyperplasia, is the most common gastrointestinal (GI) cause of protein-losing enteropathy (PLE). The clinical course of MD in childhood differs from that in adults and has often been reported to be associated with cytomegalovirus (CMV) infection. We present a case of a previously healthy 22-monthold boy presenting with PLE, who was initially suspected to have an eosinophilic GI disorder. However, he was eventually confirmed, by detection of CMV DNA using polymerase chain reaction (PCR) with gastric tissue, to have MD associated with an active CMV infection. We suggest that endoscopic and pathological evaluation is necessary for the differential diagnosis of MD. In addition, CMV DNA detection using PCR analysis of biopsy tissue is recommended to confirm the etiologic agent of MD regardless of the patient's age or immune status. Clin Endosc 2018;51:89-94
\end{abstract}

Key Words: Cytomegalovirus; Protein-losing enteropathies; Gastritis, hypertrophic; Ménétrier's disease; Child

\section{INTRODUCTION}

Ménétrier's disease (MD) is a rare disease characterized by hypertrophic gastric folds and marked protein loss through the gastric mucosa. In adults, MD is known to be an acquired premalignant disorder with a progressive clinical course, often requiring gastrectomy. ${ }^{1}$ However, pediatric $\mathrm{MD}$, an entity distinct from adult cases, has a benign course with an acute onset and spontaneous regression. ${ }^{1,2}$ Although its etiology is unclear in most cases, pediatric MD has often been linked to infections, including cytomegalovirus (CMV), Helicobacter pylori, Herpes simplex, or Mycoplasma infections. ${ }^{1}$

Received: March 7, 2017 Revised: April 14, 2017

Accepted: May 8, 2017

Correspondence: Jeana Hong

Department of Pediatrics, Kangwon National University Hospital, Kangwon National University School of Medicine, 156 Baengyeong-ro, Chuncheon 24289, Korea

Tel: +82-33-258-2483, Fax: +82-33-258-2418, E-mail: jnhongmd@gmail.com

(cc) This is an Open Access article distributed under the terms of the Creative Commons Attribution Non-Commercial License (http://creativecommons.org/ licenses/by-nc/3.0) which permits unrestricted non-commercial use, distribution, and reproduction in any medium, provided the original work is properly cited.
CMV is a significant pathogen in immunosuppressed patients. When CMV is involved in a gastrointestinal (GI) tract infection, it is rarely identifiable on routine histological examination. Therefore, it is often difficult to identify CMV as the etiologic pathogen in most cases of MD.,

We present a case of a previously healthy toddler with $\mathrm{CMV}$-associated MD, the youngest case ever reported in Korea, and a literature review of MD in Korean children.

\section{CASE REPORT}

A 22-month-old boy presented to the emergency department with a 6-day history of vomiting and poor oral intake. Approximately one week prior to presentation, he had developed a cough and rhinorrhea, and fever lasting one day. The following day, he had two to four episodes of vomiting per day. On the day of presentation, he was found to be lethargic with decreased urination.

On admission, his body weight was $12 \mathrm{~kg}$ (25-50 percentile), with a 1-kg weight gain from the most recent previous weight 


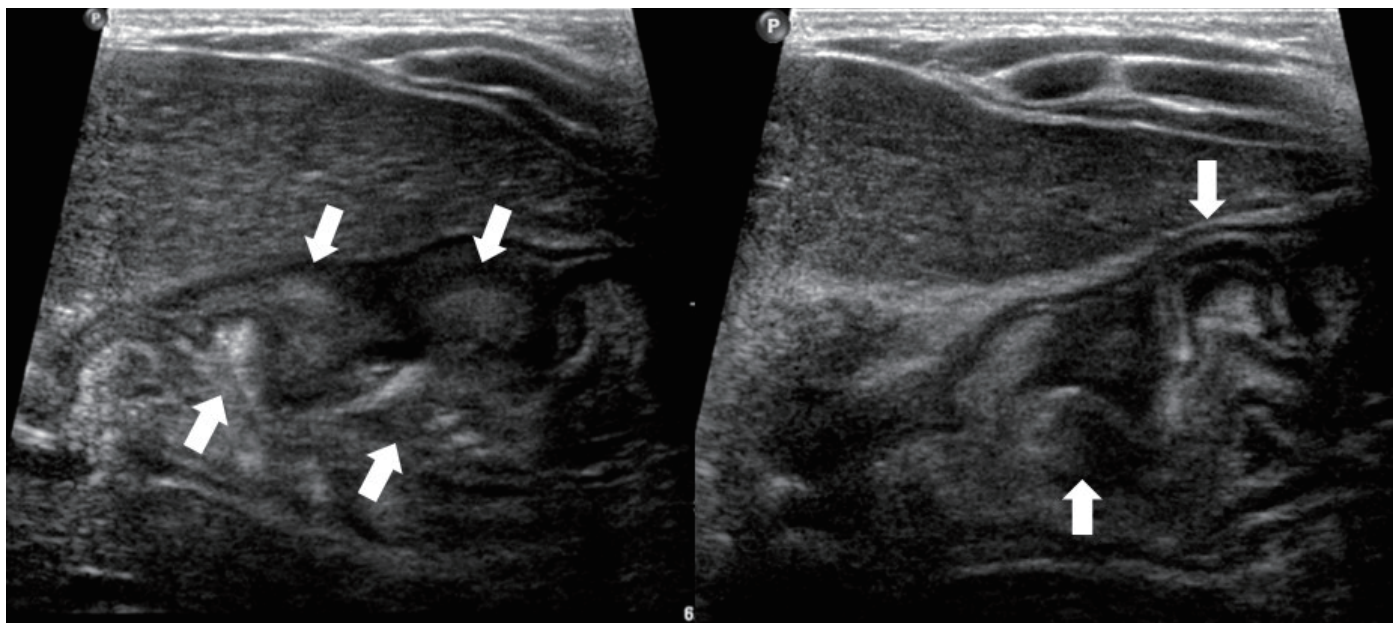

Fig. 1. Abdominal ultrasonographic finding showing thickened gastric mucosa with prominent rugae (arrows).
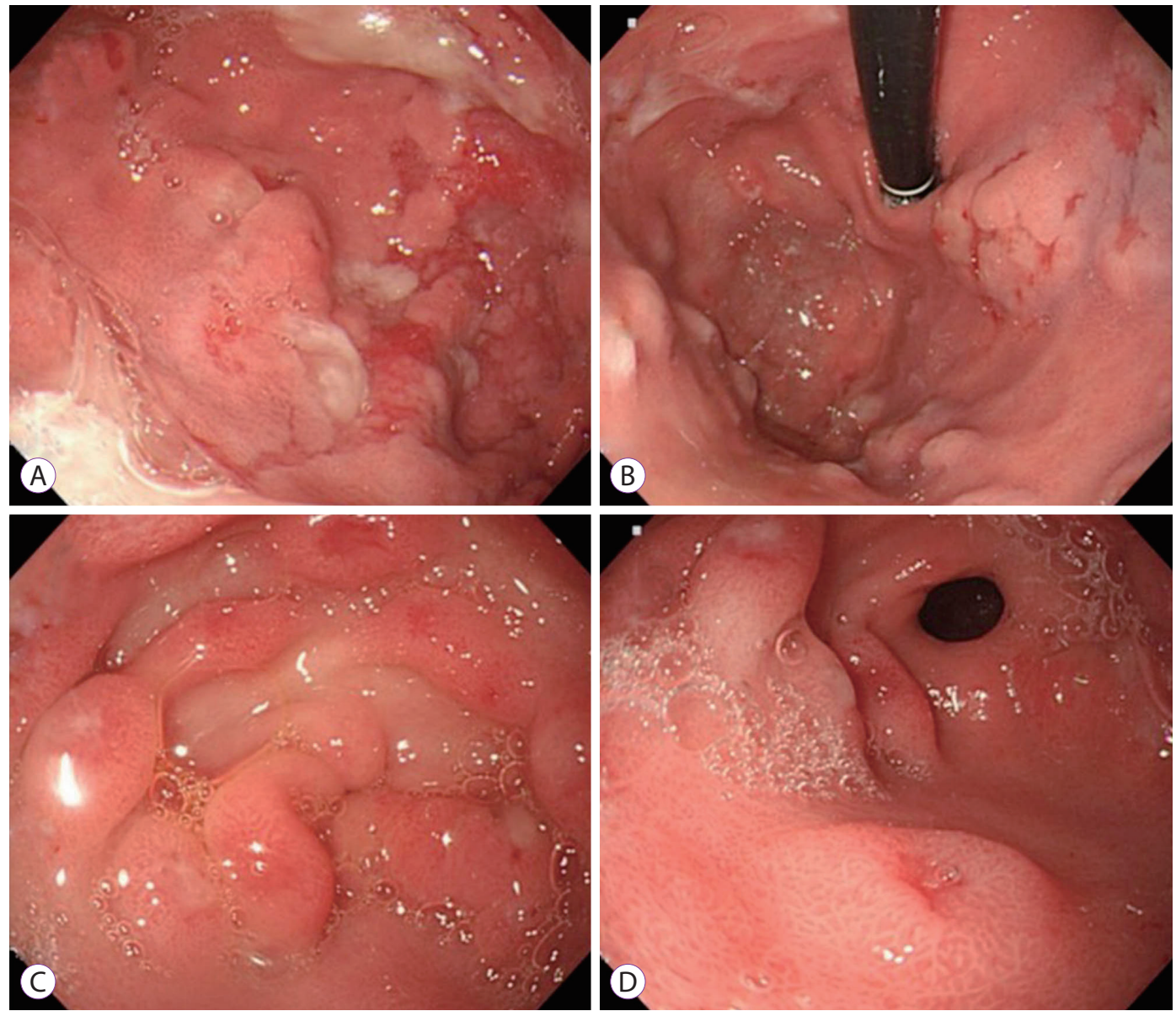

Fig. 2. Esophagogastroduodenoscopy findings. (A) A markedly edematous mucosa and hemorrhagic erosions covered with whitish mucus throughout the gastric body. (B) The hypertrophic gastric folds noted in the fundus and body. (C, D) Numerous polypoid masses with superficial ulcers diffusely distributed in the antrum.

of $11 \mathrm{~kg}$ (15-25 percentile). Physical examination revealed bilateral periorbital edema without icteric sclera and a soft, but slightly distended abdomen without hepatosplenomegaly. Although pretibial edema was absent, his scrotum was double the normal size.

Complete blood cell counts revealed a leukocyte count of $27,900 / \mathrm{mm}^{3}$, hemoglobin level of $14.2 \mathrm{~g} / \mathrm{dL}$, and a eosinophil count significantly elevated to $1,130 / \mu \mathrm{L}$. While the total serum 


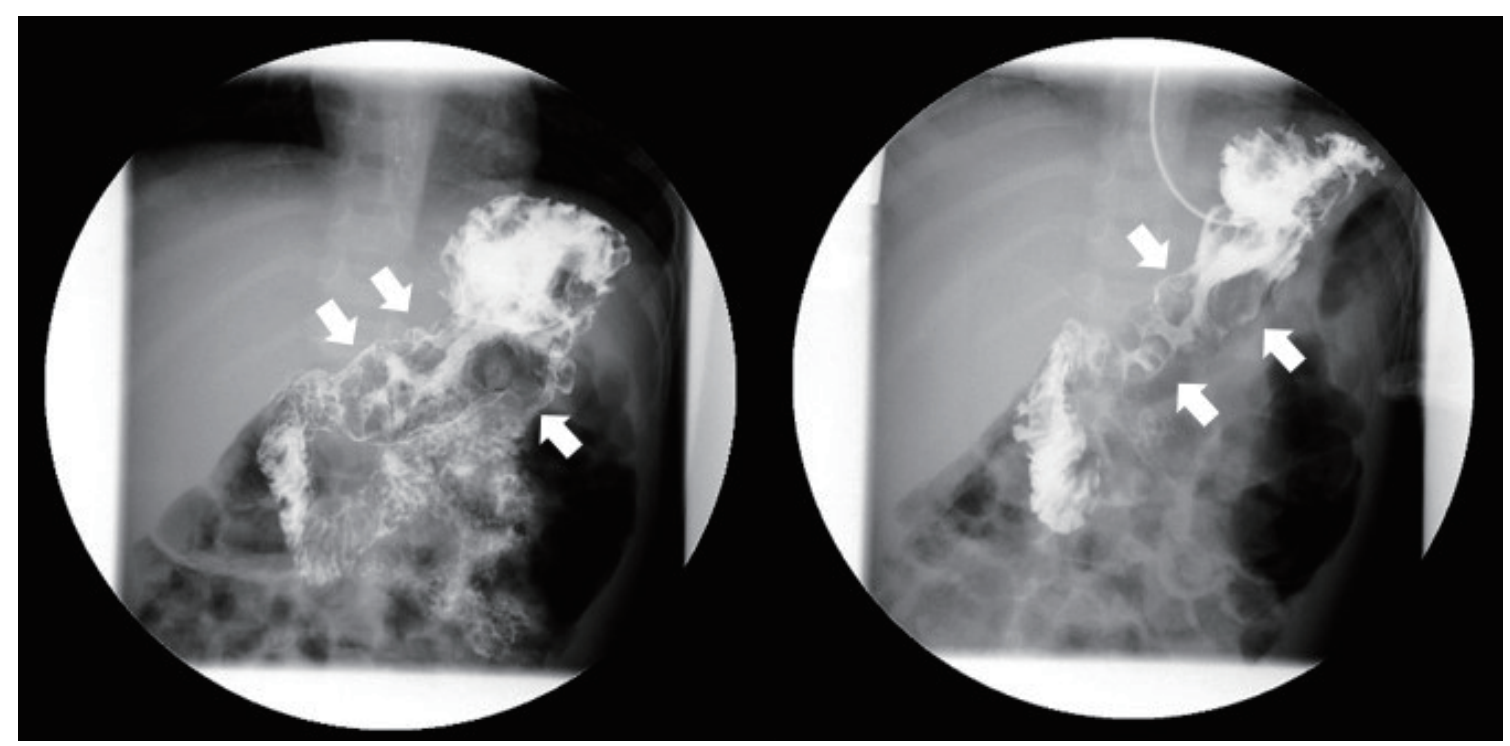

Fig. 3. Upper gastrointestinal series finding. Prominent enlarged and polypoid gastric folds of the body and antrum (arrows) with regular mucosal folds of the jejunum.
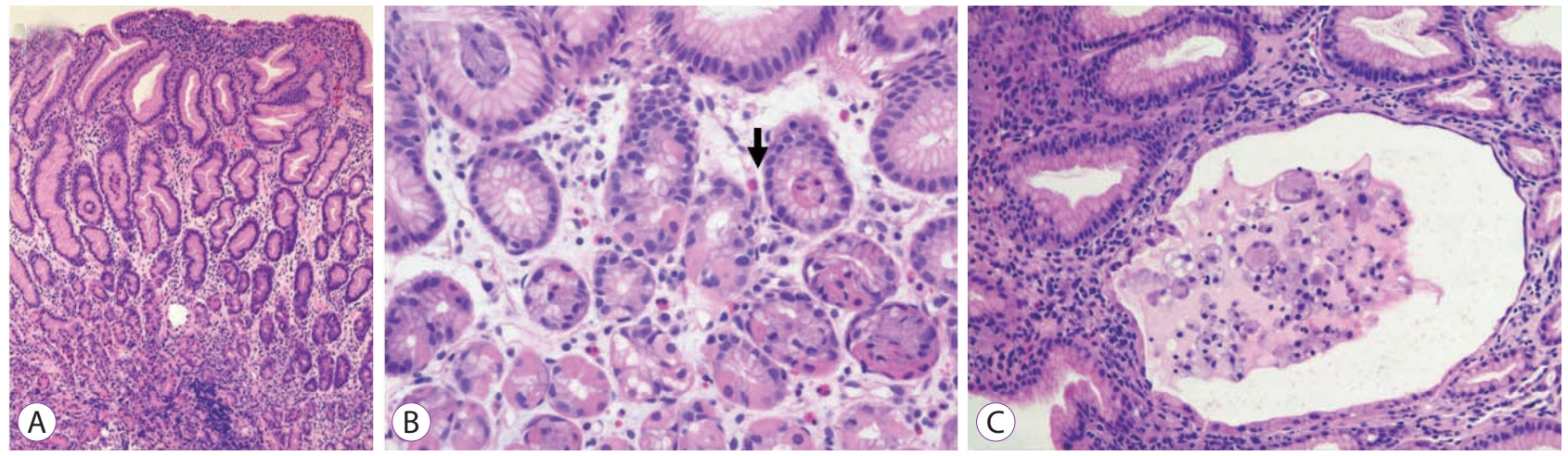

Fig. 4. Histological examinations of gastric biopsy specimens. (A) Hyperplastic foveolar cells with a corkscrew appearance (hematoxylin and eosin [H\&E] stain, $\times 100)$. (B) Scattered eosinophil (arrow) in the laminar propria where lymphocyte infiltration is not prominent (H\&E stain, $\times 200)$. (C) A few glands showing cystic dilatational changes (H\&E stain, $\times 200)$.

protein concentration was $3.6 \mathrm{~g} / \mathrm{dL}$ with an albumin level of $2.2 \mathrm{~g} / \mathrm{dL}$, the hepatic panel, electrolytes, blood urea nitrogen, creatinine, and C-reactive protein levels were within normal ranges. Urinalysis yielded normal findings. Stool examination demonstrated the presence of occult blood, without leukocytes or parasites. Fecal a1-antitrypsin clearance was found to be elevated to $68.8 \mathrm{mg} /$ day (normal: $<20 \mathrm{mg} /$ day).

Abdominal ultrasonography showed diffuse thickening of the gastric wall with prominent gastric rugae (Fig. 1). Only minimal ascites was present in the pelvic cavity. Esophagogastroduodenoscopy (EGD) revealed hemorrhagic erosions covered with whitish mucus throughout the gastric body, which had a markedly edematous mucosal background (Fig. 2). There were also numerous polypoid masses with superficial ulcers diffusely distributed in the gastric antrum. The esophageal and duodenal mucosae were relatively unremarkable. An upper GI series showed prominent gastric folds with polypoid mucosa in the body and antrum (Fig. 3).

Serological testing for CMV detected immunoglobulin (Ig) $\mathrm{M}(1.90 \mathrm{AU} / \mathrm{mL})$ on the third day and moderately elevated titers of $\operatorname{IgM}(3.39 \mathrm{AU} / \mathrm{mL})$ and $\operatorname{IgG}(63.4 \mathrm{AU} / \mathrm{mL})$ on the tenth day of admission. CMV DNA was detected using polymerase chain reaction (PCR) in urine and a CMV culture of the patient's urine was also positive. Viremia was undetectable and serum $H$. pylori IgG antibody was negative.

Histological examinations revealed foveolar hyperplasia with cystic glandular dilatations (Fig. 4). Eosinophil infiltration was found, but the eosinophil count did not exceed the minimum threshold to satisfy the diagnostic criterion of eosinophilic gastritis. ${ }^{5}$ Intranuclear CMV inclusion bodies were not detected and immunostaining with monoclonal antibody against the CMV early antigen was also negative. However, 

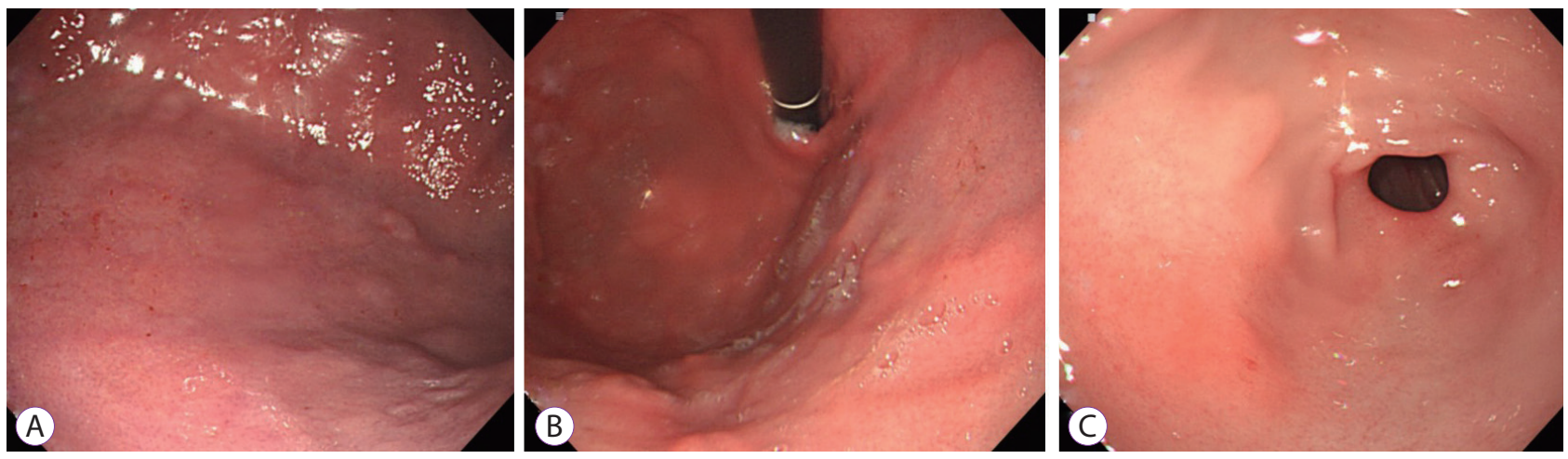

Fig. 5. Repeated gastroscopic findings performed in 4 weeks after discharge showing a healed mucosa with resolution of the erosive and polypoid lesion.

PCR for CMV DNA from the gastric biopsy specimens was positive.

During the hospital course, intravenous albumin was administered for two consecutive days, and the albumin level increased to $2.7 \mathrm{~g} / \mathrm{dL}$. He was also treated with lansoprazole. On the tenth day of admission, he was discharged with an albumin level of $3.5 \mathrm{~g} / \mathrm{dL}$ and was asymptomatic. However, his eosinophil count increased to $1,590 / \mu \mathrm{L}$.

A repeated EGD performed four weeks after discharge showed a healed mucosa with resolution of the polypoid mucosa and ulcerative lesions (Fig. 5). While intranuclear inclusion bodies were not found, a repeat CMV PCR of the gastric tissue was positive. Viral serology showed a rising IgG titer (73.2 AU/mL), while IgM antibody titers (1.82 AU/mL) decreased. The eosinophil count normalized to $340 / \mu \mathrm{L}$. Approximately four months after the initial presentation, CMV IgM was no longer detectable and IgG levels increased to $88.3 \mathrm{AU} / \mathrm{mL}$.

\section{DISCUSSION}

The pathophysiology of MD and the sequential effects of CMV on the manifestation of MD have not been clearly elucidated. Overexpression of transforming growth factor- $\alpha$ (TGFa) in affected gastric mucosal cells is suggested to play a pivotal role in MD pathogenesis. ${ }^{6}$ Through enhanced signals to the epidermal growth factor receptor (EGFR), the overexpressed TGFa stimulates foveolar mucus cell proliferation with enhanced mucin secretion. It is also involved in the widening of tight junctions between gastric epithelial cells, leading to a loss of serum protein into the GI tract, which is described as protein-losing enteropathy (PLE). ${ }^{7,8}$ In this process, CMV is considered to induce the overexpression of TGFa and sequentially activate EGFR signaling.

In almost all cases, evidence of CMV infection has been based on positive serologic findings. However it does not conclusively suggest acute infection. In addition, intranuclear inclusion bodies, a hallmark of CMV infection, are not detected through routine hematoxylin and eosin histological preparation. ${ }^{9}$ In fact, histological evidence of gastric CMV infection has been found in only one-third of cases. ${ }^{3}$ In the present case, we confirmed an active CMV GI infection by the detection of the viral nucleic acid in gastric tissue through PCR analysis although we had no histological evidence of CMV infection in multiple biopsied tissues. It has recently been considered a more sensitive assay that can detect a single copy of the virus at a considerably higher rate than immunohistochemical studies, antigenemia, or serological test. ${ }^{2}$

MD and eosinophilic GI disorder (EGID) are the most common GI causes of PLE. ${ }^{10}$ Since our patient showed significant peripheral eosinophilia with hypoalbuminemia, we initially considered the patient to have an EGID involving the upper GI tract with PLE after excluding other causes of eosinophilia. Although radiologic or endoscopic findings of hypertrophic gastric folds are characteristic features of MD, differential diagnosis should include lymphoma, gastric varices, Zollinger-Ellison syndrome, gastric involvement of Crohn's disease, hypertrophic lymphocytic gastritis, multiple polyps, and eosinophilic gastritis. ${ }^{11}$ Furthermore, a recent study reports that MD is most commonly confused with gastric polyps or a gastric involvement of polyposis syndrome. ${ }^{12}$ In this case, while endoscopic findings included polypoid gastric mucosa, rather than giant rugal folds, we favored the diagnosis of MD based on the histological findings. Moreover, the disease course was relatively short and spontaneously remitted with only supportive care, compared to EGID, which has a more protracted course. Peripheral eosinophilia, observed in most pediatric cases, is considered a hypersensitivity reaction to $\mathrm{CMV}$ infection that permits the mucosal penetration of allergens. $^{13}$

In a study reviewing 16 Korean adult cases, none was CMV-associated MD. ${ }^{14}$ However, seven cases (43.8\%) resolved spontaneously without surgical intervention; many of these cases seemed to be associated with a transient infection, al- 


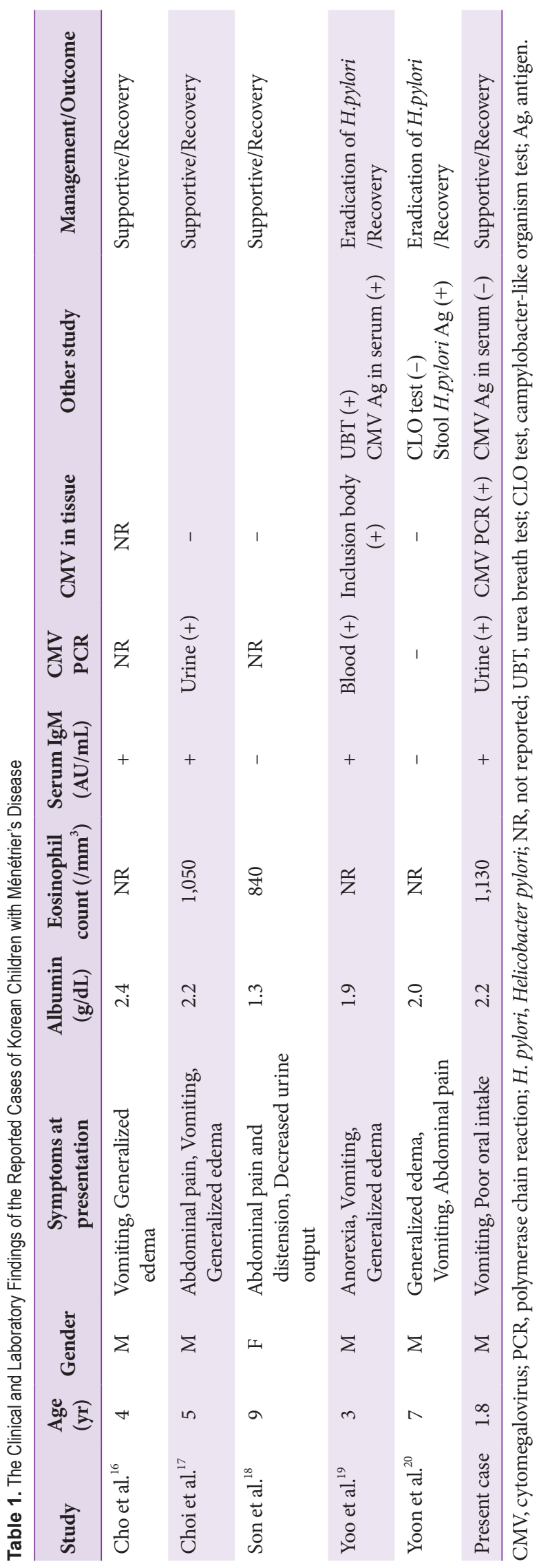

though CMV status was not documented. Recently, CMV-associated MD was reported in an immunocompetent adult, who had complete resolution without any surgical intervention or antiviral agents. ${ }^{15}$ In reported pediatric CMV-associated cases, almost all were immunocompetent. ${ }^{2}$ Therefore, we could expect that even adults who are susceptible to CMV infection may present with MD as the primary CMV infection.

We reviewed the clinical and laboratory findings of five reported cases of Korean children with MD (Table 1). ${ }^{16-20}$ Their median age was 5 (range, 3-9) years with a predominance of boys (male: female ratio of 4:1). The five cases were all previously healthy without underlying diseases. The most commonly presented symptoms were vomiting and generalized edema, diarrhea not being a prominent symptom. While three cases (75\%) showed evidence of recent CMV infections via serology, CMV was detected in the tissue of only one case although gastric biopsies were performed in all five cases. All children with CMV-associated MD fully recovered without the use of any antiviral agents. Two cases were associated with H. pylori infections, one of which had coinfection with CMV, and both cases improved with $H$. pylori eradication. Documented eosinophilia was found in two cases and normalized when symptoms improved without any specific treatment.

We suggest that MD can be induced by a primary or reactivated GI CMV infection regardless of a patient's age or immune status. Although pediatric MD is a self-limiting condition, we recommend endoscopic evaluations with tissue biopsies to establish the diagnosis of MD. In addition, CMV DNA detection using PCR analysis of endoscopically-acquired biopsy tissue is recommended for the definitive evidence of an active GI CMV infection.

Conflicts of Interest

The authors have no financial conflicts of interest.

\section{Acknowledgments} Grant.

This study was supported by 2015 Kangwon National University Hospital

\section{REFERENCES}

1. Vandenplas Y. Menetrier disease. In: Guandalini S, Dhawan A, Branski D, eds. Textbook of pediatric gastroenterology, hepatology and nutrition. Switzerland: Springer International Publishing; 2016. p. 157-158.

2. Megged O, Schlesinger Y. Cytomegalovirus-associated protein-losing gastropathy in childhood. Eur J Pediatr 2008;167:1217-1220.

3. Cieslak TJ, Mullett CT, Puntel RA, Latimer JS. Menetrier's disease associated with cytomegalovirus infection in children: report of two cases and review of the literature. Pediatr Infect Dis J 1993;12:340-343.

4. Patra S, Samal SC, Chacko A, Mathan VI, Mathan MM. Cytomegalovirus infection of the human gastrointestinal tract. J Gastroenterol Hepatol 1999;14:973-976.

5. Ko HM, Morotti RA, Yershov O, Chehade M. Eosinophilic gastritis in 
children: clinicopathological correlation, disease course, and response to therapy. Am J Gastroenterol 2014;109:1277-1285.

6. Dempsey PJ, Goldenring JR, Soroka CJ, et al. Possible role of transforming growth factor alpha in the pathogenesis of Ménétrier's disease: supportive evidence form humans and transgenic mice. Gastroenterology 1992;103:1950-1963.

7. Wang X, Huong SM, Chiu ML, Raab-Traub N, Huang ES. Epidermal growth factor receptor is a cellular receptor for human cytomegalovirus. Nature 2003;424:456-461.

8. Sferra TJ, Pawel BR, Qualman SJ, Li BU. Ménétrier disease of childhood: role of cytomegalovirus and transforming growth factor alpha. J Pediatr 1996;128:213-219.

9. Chetty R, Roskell DE. Cytomegalovirus infection in the gastrointestinal tract. J Clin Pathol 1994;47:968-972.

10. Umar SB, DiBaise JK. Protein-losing enteropathy: case illustrations and clinical review. Am J Gastroenterol 2010;105:43-49; quiz 50.

11. Trout AT, Dillman JR, Neef HC, Rabah R, Gadepalli S, Geiger JD. Case 189: pediatric Ménétrier disease. Radiology 2013;266:357-361.

12. Rich A, Toro TZ, Tanksley J, et al. Distinguishing Ménétrier’s disease from its mimics. Gut 2010;59:1617-1624.

13. Takeyama J, Abukawa D, Miura K. Eosinophilic gastroenteritis with cytomegalovirus infection in an immunocompetent child. World J Gas- troenterol 2007;13:4653-4654.

14. Lim YJ, Rhee PL, Kim YH, et al. Clinical features of Menetrier's disease in Korea. Korean J Gastrointest Endosc 2000;21:909-916.

15. Suter WR, Neuweiler J, Borovicka J, Binek J, Fantin AC, Meyenberger C. Cytomegalovirus-induced transient protein-losing hypertrophic gastropathy in an immunocompetent adult. Digestion 2000;62:276-279.

16. Cho JR, Kang SK, Kim YH, Choe YH. A case of Menetrier's disease associated with cytomegalovirus infection. Korean J Pediatr 2001;44:11971200

17. Choi WJ, Lee BY, Lee HJ, Oh HK, Hwang JB. Cytomegalovirus-induced childhood Menetrier's disease with peripheral eosinophilia. Korean J Pediatr Gastroenterol Nutr 2004;7:87-91.

18. Son KH, Kwak JJ, Park JO. A case of cytomegalovirus-negative Ménétrier's disease with eosinophilia in a child. Korean J Pediatr 2012;55:293296.

19. Yoo Y, Lee Y, Lee YM, Choe YH. Co-infection with cytomegalovirus and helicobacter pylori in a child with Ménétrier's disease. Pediatr Gastroenterol Hepatol Nutr 2013;16:123-126.

20. Yoon J, Ahn MB, Maeng L-S, Kim SY. A case of pediatric Ménétrier's disease associated with helicobacter pylori infection. Korean J Helicobacter Up Gastrointest Res 2014;14:288-291. 